\title{
Is It Worth the Wait? Patient Perceptions of Wait Time at a Primary Care Clinic
}

Benjamin Pockros, BA; Samuel Nowicki, BS; Carole Vincent, MD

\begin{abstract}
BACKGROUND AND OBJECTIVES: A patient's wait to see a provider before scheduled appointments may impact their experience at the primary care clinic. This survey study examined how long patients are willing to wait, where they prefer to wait, and whether punctual care in the clinic may be more prioritized than quality care.
\end{abstract}

METHODS: We disseminated a survey in the waiting room of an urban adult primary care office to assess patient perceptions and evaluate the importance of punctuality. We completed subgroup analyses to examine any differences by age and gender in patient expectations and values.

RESULTS: The survey was completed by 180 respondents ( $92 \%$ response rate). Patients report they can wait up to 20 minutes (95\% Cl 19.1-22.0) before seeing their provider. A subgroup analysis determined that age alone cannot be used as a screening tool to identify patients who require the most punctual care. Women expressed a more explicit preference for quality rather than punctuality compared to men $(P=.0017)$.

CONCLUSIONS: Results suggest that patients are unwilling to forego quality care for punctuality alone. Our findings may help providers better understand patient perceptions of waiting at a primary care clinic.

(Fam Med. 2021;53(9):796-9.)

doi: 10.22454/FamMed.2021.790286

$\mathbf{T}$ he patient's wait to see a provider before a scheduled appointment has been shown to be one of the largest sources of discontent during the clinical encounter. ${ }^{1-3}$ Patient satisfaction is an important outcome of health care services and can affect compliance with medical advice, service utilization, and the clinician-patient relationship. ${ }^{4-7}$ Patient satisfaction can lead to improved health outcomes, reduced mortality through behavior changes, and better treatment adherence. ${ }^{8-10}$ Therefore, wait times are indeed a component of patient satisfaction, but also an important feature of quality care.

As patient satisfaction continues to play a growing role during the clinical visit, a more detailed understanding of patient expectations and preferences should be critically examined. Many studies have demonstrated the clear inverse relationship between wait time and patient satisfaction, ${ }^{11-14}$ but few studies have examined how long patients are willing to wait and if they ever value punctuality more than quality. There is a paucity of research available that describes the patient's expectation to wait. The purpose of this study was to examine the patient perceptions of wait time by disseminating a survey in the waiting room of a single adult primary care office.

\section{Methods}

We invited all patients in the waiting room of a single adult primary care office in Quincy, Massachusetts, to complete a survey. Survey collection took place every Monday from $1 \mathrm{pm}$ to $3 \mathrm{pm}$ between August 2019 and December 2019 in attempt to maintain consistency and reduce possible confounding variability. The adult primary care office included three physicians and was located in an urban community that served patients with private insurance, Medicare, and Medicaid. The research staff approached all patients in the waiting room and administered a paper survey for patients who consented to participate. Patients were asked to submit their responses in a dropoff container when they completed the survey to reduce the possibility of participation bias. Our university's institutional review board considered this study exempt from review because it did not involve patient identifying information.

We designed survey questions to examine current perceptions of wait time at a primary care clinic. No survey has been previously validated to measure patient perceptions and

From Tufts University School of Medicine, Boston, MA (Mr Pockros and Mr Nowicki); and Atrius Health, Internal Medicine, Quincy, MA (Dr Vincent). 
expectations of wait time. Five random patients initially reviewed our survey to improve reliability and validity. This pilot cohort was cognitively interviewed to provide feedback on the survey. ${ }^{15}$ This initial cohort all reported the survey to be straightforward and appropriate.

Patients were asked to provide their age and gender to collate demographic information. The survey included four questions to measure the perceptions of waiting, including priorities, preferences, and an estimate of a reasonable wait time (Figure 1).

We performed a statistical analysis using Excel version 15.40 software (Microsoft Corp, Redmond, WA). We performed a subgroup analysis comparing male and female responses using a two-tailed populational proportion test and a Mann-Whitney $U$ test. We conducted additional subgroup analysis comparing age groups using a Fischer
Exact Test and an analysis of variance test.

\section{Results}

One hundred ninety-six patients were approached in the waiting room, of which 180 agreed to complete the survey (92\% response rate). Characteristics of the study sample and summary statistics are presented in Table 1 . Only $2 \%$ of respondents expressed an explicit priority to "remain on schedule during my day," compared to $53 \%$ of respondents who marked quality care as the single-most important priority. Eighty percent of respondents revealed they had flexible schedules, although $32 \%$ of those respondents noted they still prefer punctuality when possible. Forty-four percent of respondents answered a preference to wait in the waiting room, and $30 \%$ marked they had no preference. Patients reported they can generally wait up to 20.53 minutes (95\% CI

Figure 1: Survey

We are hoping to get your input on how wait times affect your care, and how we can better help you. Please take five minutes to answer this brief and anonymous survey. Thank you!

Please circle one answer for each of the following questions:

1) Male or Female or Other

2) Age: $<25 y / 0 \quad 25-45 y / 0 \quad 45-65 y / 0 \quad 65+y / o$

3) When I schedule an appointment to be seen by my provider:

a. It is most important that I receive quality time to talk with my physician.

b. It is most important to remain on schedule during my day.

c. I value punctuality and quality care equally.

4) Typically, when I plan my day around my medical appointments:

a. I create flexibility in my schedule in case the appointment takes longer than expected.

b. I have a strict schedule and expect my appointment to run as scheduled

c. I prefer to be seen on time, but truthfully, my days are often flexible

5) If my provider was running 30 minutes behind schedule:

a. I would prefer to wait in the examination room alone (or with whoever accompanied you to the appointment) until the physician arrives.

b. I would prefer to wait in the waiting room until the physician is ready.

c. I have no preference.

6) The amount of time I can generally wait to be seen by my provider is up to minutes.

19.1-22.0) before seeing their provider.

We conducted a subgroup analysis to examine any major differences in preferences and values between gender (Table 2) and age (Table 3); $64 \%$ of women noted they prioritized quality compared to $40 \%$ of men $(P=.0017)$. Likewise, $4 \%$ of men noted they prioritize punctuality compared to quality at their visits, while no women selected that answer choice $(P=.039)$. A subgroup analysis by age groups found no significant differences.

\section{Discussion}

This study builds on previous literature by finding that patients arrive to the clinic with an expectation to wait up to 20 minutes (95\% CI 19.122.0) and that patients are almost entirely unwilling to sacrifice quality care for punctuality alone. Providers may be able to leverage this expectation and create flexibility within their schedule to accommodate different patient needs. A significant proportion of patients (nearly one in five) self-identify as having inflexible schedules. Practices should strive to identify these patients to enhance satisfaction and care goals. Interestingly, patients aged 25 to 45 years do not report more inflexible schedules compared to other age groups. Therefore, age alone cannot be used as a screening tool to identify patients who require the most punctual care. Practices should not assume that older patients are more amenable to longer waits due to more flexible schedules. Older patients may experience more barriers to care compared to younger patients, such as scheduling multiple appointments on the same day or reliance on transportation.

Future research should continue to explore how practices can reduce wait time burden and customize the clinical experience based on patient preferences. Strategies including self-rooming, physician block scheduling, and workspace redesign have demonstrated improved patient satisfaction. ${ }^{16-18}$ As more clinics begin to offer Telemedicine appointments,

VOL. 53, NO. 9 • OCTOBER 2021 
Table 1: Demographics and Summary Statistics

\begin{tabular}{|c|c|c|}
\hline Demographics/Survey Items & Total Respondents ( $\mathrm{N}=\mathbf{1 8 0})$ & $\begin{array}{l}\text { Percent of Total } \\
\text { Respondents }\end{array}$ \\
\hline \multicolumn{3}{|l|}{ Self-reported Gender } \\
\hline Female & 104 & 58 \\
\hline Male & 76 & 42 \\
\hline Other & 0 & 0 \\
\hline \multicolumn{3}{|l|}{ Age in Years } \\
\hline$<25$ & 11 & 6 \\
\hline $25-45$ & 42 & 23 \\
\hline $46-65$ & 73 & 41 \\
\hline $66+$ & 54 & 30 \\
\hline \multicolumn{3}{|l|}{ Priority During Clinical Visit } \\
\hline Quality & 96 & 53 \\
\hline Punctuality & 3 & 2 \\
\hline Quality and punctuality equally & 81 & 45 \\
\hline \multicolumn{3}{|l|}{$\begin{array}{l}\text { Scheduling for Clinical Visit } \\
\end{array}$} \\
\hline Flexible schedule & 87 & 48 \\
\hline Strict schedule/busy & 35 & 19 \\
\hline Punctual preference, but flexible schedule & 58 & 32 \\
\hline \multicolumn{3}{|l|}{ Preference for Waiting Location } \\
\hline Waiting room & 78 & 44 \\
\hline Examination room & 46 & 26 \\
\hline No preference & 55 & 30 \\
\hline Acceptable Time to Wait for Doctor (in Minutes) & \multicolumn{2}{|c|}{$20.53,95 \%$ CI $19.1-22.0$} \\
\hline
\end{tabular}

Table 2: Subgroup Analysis by Self-reported Gender

\begin{tabular}{|c|c|c|c|c|c|c|}
\hline Priority During Clinical Visit & Quality & $P$ Value & Punctuality & $P$ Value & Both & $P$ Value \\
\hline Female $(\mathrm{n}=104)$ & $64 \%$ & .0014 & $0 \%$ & .039 & $36 \%$ & .008 \\
\hline Male $(\mathrm{n}=76)$ & $40 \%$ & - & $4 \%$ & - & $56 \%$ & - \\
\hline Scheduling for Clinical Visit & Flexible & & Strict/Busy & & In Between & \\
\hline Female & $55 \%$ & .046 & $21 \%$ & .50 & $24 \%$ & .007 \\
\hline Male & $40 \%$ & - & $17 \%$ & - & $43 \%$ & - \\
\hline Preference for Waiting Location & Exam Room & & Wait Room & & No Preference & \\
\hline Female & $27 \%$ & .65 & $48 \%$ & .18 & $25 \%$ & .061 \\
\hline Male & $24 \%$ & - & $38 \%$ & - & $38 \%$ & - \\
\hline Acceptable Time to Wait for Doctor & & & Minutes & & & \\
\hline Female & & & $18.89+/-8.50$ & .009 & & \\
\hline Male & & & $22.76+/-11.35$ & - & & \\
\hline
\end{tabular}

particularly in response to the COVID-19 pandemic, wait time may have less of an impact on satisfaction than previously reported, since patients can continue their normal routine at home or work while waiting. Future research could adapt this survey for virtual patients and reexamine the perceptions of punctuality and quality during virtual appointments.

The generalizability of the findings may be limited because the study was conducted at a single site. Patients completed the survey at different time points of their wait. It is possible that patients who completed the survey after waiting extensively, or after immediately arriving to the clinic, could have variable reflections about wait time. Patients only reflected on their preferences before the clinical visit. It is possible that patients could disclose different priorities after the visit. 
Table 3: Subgroup Analysis by Age

\begin{tabular}{|c|c|c|c|c|}
\hline Priority During Clinical Visit & Quality & Punctuality & Both & $P$ Value \\
\hline$<25(\mathrm{n}=11)$ & $73 \%$ & $0 \%$ & $27 \%$ & .33 \\
\hline $25-45(n=42)$ & $48 \%$ & $2 \%$ & $50 \%$ & - \\
\hline $46-65(\mathrm{n}=73)$ & $47 \%$ & $3 \%$ & $50 \%$ & - \\
\hline $66+(\mathrm{n}=54)$ & $63 \%$ & $0 \%$ & $37 \%$ & - \\
\hline Scheduling for Clinical Visit & Flexible & Strict/Busy & In Between & \\
\hline$<25$ & $46 \%$ & $9 \%$ & $45 \%$ & .18 \\
\hline $25-45$ & $45 \%$ & $31 \%$ & $24 \%$ & - \\
\hline $46-65$ & $47 \%$ & $20 \%$ & $33 \%$ & - \\
\hline $66+$ & $54 \%$ & $11 \%$ & $35 \%$ & - \\
\hline Preference for Waiting Location & Exam Room & Wait Room & No Preference & \\
\hline$<25$ & $36 \%$ & $18 \%$ & $46 \%$ & .70 \\
\hline $25-45$ & $24 \%$ & $50 \%$ & $26 \%$ & - \\
\hline $46-65$ & $26 \%$ & $44 \%$ & $30 \%$ & - \\
\hline $66+$ & $25 \%$ & $43 \%$ & $32 \%$ & - \\
\hline Acceptable Time to Wait for Doctor & & Minutes & & . \\
\hline$<25$ & & $20.91+/-8.31$ & & .81 \\
\hline $25-45$ & & $19.40+/-11.38$ & & - \\
\hline $46-65$ & & $20.48+/-9.65$ & & - \\
\hline $66+$ & & $21.39+/-9.68$ & & - \\
\hline
\end{tabular}

\section{Conclusion}

Data gathered from this survey study of patients at an adult primary care clinic provide important information regarding perceptions of wait time. Providers can leverage patient expectations to enhance satisfaction.

CORRESPONDING AUTHOR: Address correspondence to Mr Benjamin Pockros, Tufts University School of Medicine, 145 Harrison Ave, Boston, MA 02111. Ben.pockros@tufts.edu.

\section{References}

1. Bleustein C, Rothschild DB, Valen A, Valatis E, Schweitzer L, Jones R. Wait times, patient satisfaction scores, and the perception of care. Am J Manag Care. 2014;20(5):393-400.

2. Braddock CH III, Snyder L. The doctor will see you shortly. The ethical significance of time for the patient-physician relationship. J Gen Intern Med. 2005;20(11):1057-1062. doi:10.1111/j.1525-1497.2005.00217.x

3. Michael M, Schaffer SD, Egan PL, Little BB, Pritchard PS. Improving wait times and patient satisfaction in primary care. J Healthc Qual. 2013;35(2):50-59. doi:10.1111/jhq.12004

4. Kahan B, Goodstadt M. Continuous quality improvement and health promotion: can CQI lead to better outcomes? Health Promot Int. 1999;14(1):83-91. doi:10.1093/heapro/14.1.83

5. Hjortdahl P, Laerum E. Continuity of care in general practice: effect on patient satisfaction. BMJ. 1992;304(6837):1287-1290. doi:10.1136/ bmj.304.6837.1287
6. Swenson SL, Buell S, Zettler P, White M, Ruston DC, Lo B. Patient-centered communication do patients really prefer it? J Gen Intern Med. 2004;19(11):1069-1079. doi:10.1111/j.15251497.2004.30384.x

7. Zandbelt LC, Smets EM, Oort FJ, Godfried MH, de Haes HC. Medical specialists' patientcentered communication and patient-reported outcomes. Med Care. 2007;45(4):330-339. doi:10.1097/01.mlr.0000250482.07970.5f

8. Jha AK, Orav EJ, Zheng J, Epstein AM. Patients' perception of hospital care in the United States. N Engl J Med. 2008;359(18):1921-1931 doi:10.1056/NEJMsa0804116

9. Lyu H, Wick EC, Housman M, Freischlag JA Makary MA. Patient satisfaction as a possible indicator of quality surgical care. JAMA Surg. 2013;148(4):362-367. doi:10.1001/2013.jamasurg. 270

10. Glickman SW, Boulding W, Manary M, et al. Patient satisfaction and its relationship with clinical quality and inpatient mortality in acute myocardial infarction. Circ Cardiovasc Qual Outcomes. 2010;3(2):188-195. doi:10.1161/ CIRCOUTCOMES.109.900597

11. Howard M, Agarwal G, Hilts L. Patient satisfaction with access in two interprofessional academic family medicine clinics. Fam Pract. 2009;26(5):407-412. doi:10.1093/fampra/ cmp049

12. Leddy KM, Kaldenberg DO, Becker BW. Timeliness in ambulatory care treatment. An examination of patient satisfaction and wait times in medical practices and outpatient test and treatment facilities. J Ambul Care Manage. 2003;26(2):138-149. doi:10.1097/00004479200304000-00006
13. Anderson RT, Camacho FT, Balkrishnan $\mathrm{R}$. Willing to wait?: the influence of patient wait time on satisfaction with primary care. BMC Health Serv Res. 2007;7(1):31. doi:10.1186/1472-6963-7-31

14. Camacho F, Anderson R, Safrit A, Jones AS, Hoffmann P. The relationship between patient's perceived waiting time and officebased practice satisfaction. N C Med J. 2006;67(6):409-413. doi:10.18043/ncm.67.6.409

15. Willis GB, Artino AR Jr. What do our respondents think we're asking? Using cognitive interviewing to improve medical education surveys. J Grad Med Educ. 2013;5(3):353-356. doi:10.4300/JGME-D-13-00154.1

16. Koonce T, Neutze D. Improving patient care through workspace renovation and redesign: A lean approach. Fam Med. 2020;52(6):435-439. doi:10.22454/FamMed.2020.429243

17. Murray M, Berwick DM. Advanced access: reducing waiting and delays in primary care. JAMA. 2003;289(8):1035-1040. doi:10.1001/ jama.289.8.1035

18. Kamnetz S, Marquez B, Aeschlimann R, Pandhi N. Are waiting rooms passé? A pilot study of patient self-rooming. J Ambul Care Manage. 2015;38(1):25-28. doi:10.1097/ JAC.0000000000000045 